\title{
Whether Obesity Needs to be Addressed in Pre-Pregnancy Advice?
}

\author{
SZA NASREEN
}

\begin{abstract}
Summary:
Objective: When obesity need to be addressed, during pre pregnancy obesity is common and it adversely affects the maternal and perinatal outcomes. Maternal obesity has major impact on health service, specially on in relation to the level of care required, the cost and resources implications, complications and risk to the mothers and infant.
\end{abstract}

Methods and Materials: It was the prospective study 500 pregnant women ( 250 were obese and 250 were normal), The period of 3 years from January 2004 to December 2008. All the events during antenatal, during delivery and postnatal were recorded, and compare the outcomes.

Result: We found pre-eclampsia ( 10 for obese and 2 for normal, $p=0.01$ ), Positive OGTT 100 for obese and 8 for

\section{Introduction}

Obesity is a serious public health problems and its prevalence is increasing globally in all age group. ${ }^{1}$

During pregnancy along with increases the obstetrical risk.

International research has highlighted the fact that maternal obesity has implications for both mother and her infant.

Dr. Laura Riley MD, chair of the committee on obstetrician and gynaecologist remarked, " Pregnant obese women are at risk of pre-eclamsia, Gestational diabetes, caesarean delivery and post partum infection. At the same time, the fetus is at increased risk for neural tube defects, birth trauma and late fetal death." 2

It is well known that several researcher revealed obesity increases the chances of medical complications during pregnancy.

Address of correspondence: Dr. Shaikh Zinnat Ara Nasreen, Associate Professor, Dept. of Obst. \& Gynaecology, Z H Sikder women's Medical College \& Hospital, Monica Estate, West Dhanmondi, Dhaka- 1209

Received: 3, June, 2008

Accepted: 2 June, 2009 normal $P=5.72, P P H 25$ for obese and 5 for non obese $P$ $=0.00021$, wound infection 5 for obese and one in non obese group $p=0.0003$, others like UTI, we got 60 for obese and 15 for non obese $P=1.7401$. Pueperial sepsis 3 in obese and 1 for non obese $p=0.3131$. Pre eclapsia, $P P H$ and wound infection shows significantly high in obese group. Similarly NICU admission, macrosomia and fetal distress were more in obese pregnant than non obese women. So pregnancy among obese women should classified as high risk pregnancy. From the study we concluded that weight reduction before pregnancy need to be discussed as pre-pregnancy counseling.

Key words: obesity; pre-pregnancy; counselling

(J Bangladesh Coll Phys Surg 2009; 27: 144-147)

Mr. Chu's team collected data on 13,442 pregnancies study found hospital cost and stay was high and longer in obese women than normal weight women. ${ }^{3}$

Healthcare professionals in north east of England felt that maternal obesity has a major impact on health care services and resource, on the health of both mother and child and on the psychological well being of the mother. ${ }^{4}$

Rapid increasing in prevalence of obesity all over the world, obesity during pregnancy is a now common high risk obstetrical condition affecting maternal health, fetal health and health care economy.

Several studies all over the world showed the risks of obesity and pregnancy. Possibly we did not have yet any study in our country to see such effect. Therefore the objective of this study was to estimate how obese women differs from non obese women in their prenatal and maternal outcome in Bangladesh.

The hypothesis of the study is to recommend wt. loss before getting pregnant.

Methods and Material

This was designed as a prospective study conducted in Z H Sikder women's Medical College and Hospital 
during January 2004 to December 2008. 500 pregnant women were recruited.

Based on WHO classification BMI ( Body mass index) was determined at booking during gastation ( 10-12 wks) taking hieght and weight. BMI was initially divided into four catagories $\mathrm{BMI}<19.9 \mathrm{Kg} / \mathrm{m}^{2}$ ( under weight); BMI $20-24.9 \mathrm{~kg} / \mathrm{m}^{2}$ ( Normal weight) ; BMI $25-29.9 \mathrm{~kg} / \mathrm{m}^{2}$ ( Over weight) BMI $30-34.9 \mathrm{~kg} / \mathrm{m}^{2}($ Obese). All requested women $(\mathrm{n}=500)$ were enrolled. 250 obese and 250 normal weight were taken as study and control group respectively.

All the events till delivery and pueparium were documented in the ANC (antenatal) cards. The complains, clinical findings and investigations, results, mode of delivery, any complications, neonatal outcome were recorded. Along with routine investigations OGTT was done 28, 32 and 36 weeks.

Main outcome measures, Antenatal complication like pre-eclampsia, Pregnancy induce hypertention, GDM ( Gestational diabetes), UTI, rate of C/S, PPH, Wound Infection and thromboembolic disorder.

For infant, late fetal death, fetal distress, macrosomia, birth trauma, shoulder dystocia and NICU admission.

Underweight and obese women having any medical complications were excluded from the study. Written consent from academic authority of hospital and patients were taken.

Statistical analysis was done using microsoft excel software. Chi square test were applied to detect any statistical significance in the difference between the numbers of complications in the two groups of mothers. $\mathrm{P}$ value less than 0.05 was considered to be the cut off point of level of statistical significance.

\section{Result}

Out of 500 singleton pregnancy 250 were obese and 250 were normal weight. ( Table 1)

\section{Table-I}

\begin{tabular}{lccc}
\multicolumn{4}{c}{$\begin{array}{c}\text { Demographic character of women } \\
\text { with different BMI }\end{array}$} \\
BMI & $\begin{array}{c}\text { Number } \\
\mathrm{N}=550\end{array}$ & $\begin{array}{c}\text { Age } \\
\text { (mean+SD) }\end{array}$ & Gestational \\
\hline Normal weight & 250 & $29.3+5.8$ & $29.1+16.2$ \\
Obese & 250 & $28.9+8.3$ & $29.2+2.6$ \\
\hline
\end{tabular}

We found pre eclamsia ( 10 for pbese and 2 for normal pregnant, $\mathrm{P}=0.01$ ), Positive OGTT ( 100 for obese and 8 for non obese, $\mathrm{p}=5.77$ ), Post partum haemorrhage ( 25 cases in obese and 5 cases for non obese, $\mathrm{p}=0.0002$ ), wound infection in obese 5 cases and only one in non obese $\mathrm{p}=0.0003$ ). Regarding other complication like UTI we got 60 cases for obese and 15 cases for non obese, $p=1.740$, puerperal sepsis ( 3 cases for obese and 1 case for non obese, $p=$ 0.315 , Asymptomatic bacteuria 30 cases for obese and 5 cases for non obese $\mathrm{p}=1.76$. ( Figure 1)

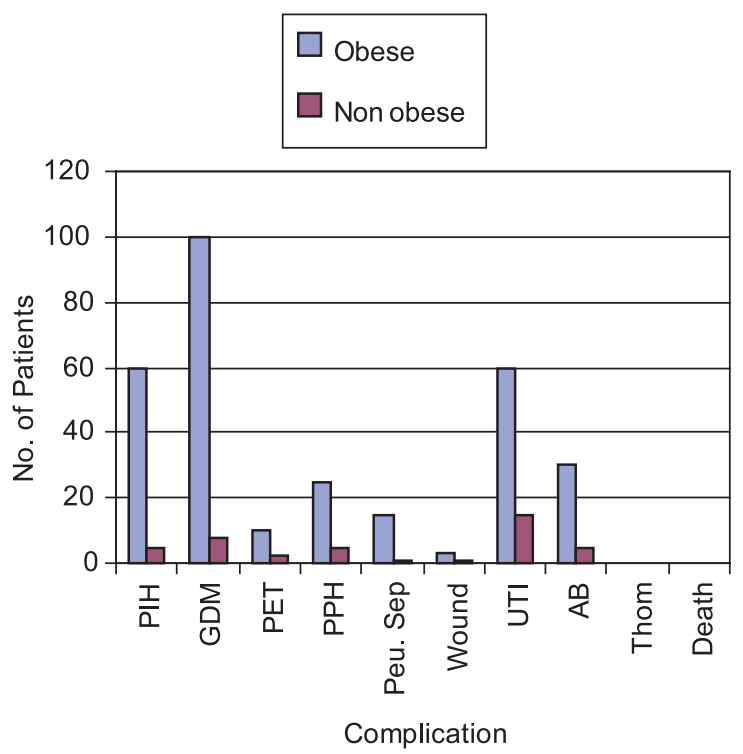

Fig.-1: showing complication among obese and non obese pregnant women

Value for pre eclampsia, PPH and wound infection shows highly significant.

Regarding perinatal complication NICU admission was higher for babies of obese than non obese ( $20 \mathrm{vs}$ 2), Also Macrosonia more in obese ( 10 vs $1 \mathrm{p}$ $=0.006)$, Fetal distress was more in obese group than non obese ( 10 vs $2 \mathrm{p}=0.01)$. Table 2

Table-II

\begin{tabular}{lccccc}
\multicolumn{5}{c}{ Perinatal Complication } \\
Complications & $\begin{array}{c}\text { Obese } \\
\text { group }\end{array}$ & $\%$ & $\begin{array}{c}\text { Non Obese } \\
\text { Group }\end{array}$ & $\%$ & P-Value \\
\hline Macrosonia & 10 & $4 \%$ & 1 & $.4 \%$ & 0.006 \\
NICU admission & 20 & $8 \%$ & 2 & $.8 \%$ & 8.67 \\
Fetal Distress & 10 & $4 \%$ & 2 & $.8 \%$ & 0.01 \\
\hline
\end{tabular}


We do not have any patient with thromboembolic disorder or maternal and late fetal death. No congetital anomalies were found in either group. One cubitus valgus was found in normal pregnant women.

Caesarean section rate was higher in obese than non obese ( 88 vs 198 and interestingly most of the C/S were higher in $1^{\text {st }}$ stage than $2^{\text {nd }}$ stage of labour in both group ( Figure 2)

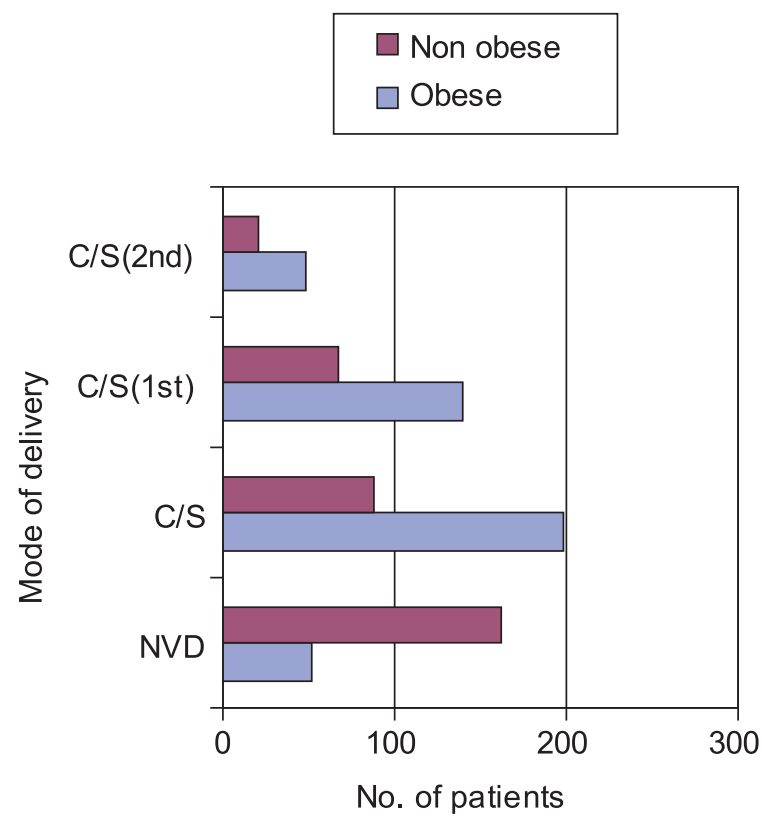

Fig.-2: Showing mode of delivery

\section{Discussion}

Several studies have documented the increased risks of adverse outcome associated with obesity and pregnancy.

Our study reflected there is increase risk of antenatal complication, c/s, postnatal complication, perinatal complication and NICU admission.

Though we had not any maternal death and late fetal death in either group of pregnant women but confidential enquiry of maternal death 2002 in U.K. showed MMR is $50 \%$ more in obese pregnant women than normal general population. ${ }^{5}$

This finding is very important warning for obese women who are planning to get pregnant.

From this study we found many of antenatal complication such as PIH, pre eclampsia, GDM and DM. This findings resemble to Freider's finding. ${ }^{3}$

Where they emphasized about pre eclampsia diabetes, deep vein thrombosis, macrosonia, increase
$\mathrm{C} / \mathrm{S}$ rate all are more with the obese pregnant than general population.

Freider also said " This is all just example of the massive problem that obesity cost on society, both to individual health as well as the economic cost to our institution. ${ }^{3}$

Regarding intrapartum complication we showed that rate of $\mathrm{C} / \mathrm{S}$ both $1^{\text {st }}$ stage and $2^{\text {nd }}$ stage $\mathrm{C} / \mathrm{S}$ is more with the obese than non obese pregnant women.

Similar finding were noticed by several studies. Despite this significant clinical problems, not much studies have explored the underlying mechanism of pathogenesis for association between obesity and raised caesarian section rate.

Most clinician suspect that the rise in caesarean section rate associated with obesity is due to obstructed labour caused by increased deposition of soft tissue in the maternal pelvis and large babies.

But recently a very promising study of J Zhang et al from Liverpool women's hospital and university concluded that myometrium of obese women contracted with less force and frequency and had less $\mathrm{Ca}^{2+}$ flux then that of normal. ${ }^{6}$

Most of $\mathrm{C} / \mathrm{S}$ occurs due to delay in $1^{\text {st }}$ stage. This conclusion is very much consistent with the findings of Cran SS et al, Loverro G et al and wei'ss JL et al's study.

Maternal obesity and hypercholestromia are associated with poor uterine contractility. Which contradicts the finding of young TK et al study which showed that $\mathrm{C} / \mathrm{S}$ is more in $2^{\text {nd }}$ stage of labour mostly because of increased soft tissue mass. ${ }^{7}$

PPH was more in obese group in our study. This study is same with the result of Pitchard et al and Keland K. Again PPH could be result of high cholesterol levels affect the effectiveness of uterine contraction. ${ }^{8}$

Pueperal sepsis, wound infection and urinary tract infection were higher in our study group. Similarly the study of Lashan et al and Umme R et al. They also showed length of hospital stay and level of care required were more in obese pregnant women. ${ }^{9}$

All the study of kumari AS et al, Rosenberg TT and Cedergreen showed that perinatal morbidities such as fetal distress, macrosomia, Birth trauma and feeding difficulties are more in obese pregnant than normal weight women. ${ }^{10}$

Also we had more rate of macrosomia, fetal distress and NICU admission more in study group. 
Pamela Salsbery had study of 3000 child which suggested a mother's weight within a month or two before she became pregnant had the greatest impact on child's weight. ${ }^{11}$

'They recommended prevention of childhood obesity needs to begin before a women ever gets pregnant.'

In health Day News ( $3^{\text {rd }}$ Feb, 2005) The panel of experts commented that overweight and obese women suffer, more pregnancy complication and their babies are more likely to have medical problem at birth, panelist also found admission to NICU higher incidence of neural tube defect in obese group.

From our study we did not find any congenital anomalies with obesity rather one case of club food in control group.

Probably this was an incidental finding.

Our study and all the mentioned studies revealed that obese women who gets pregnancy is at risk of having higher antenatal, intranatal, postnatal complication. We do not look any relation of postdated and preterm labour but very recently information available, higher maternal BMI in the $1^{\text {st }}$ trimester and through out pregnancy are associated with increase risk of postdated pregnancy and increase likelihood of complication. ${ }^{12}$ The study of Lateran suggested that whose body mass index is 30 or above have approximately double the risk of having an affected child.

We have some study limitation, the $1^{\text {st }}$ of all the sample size is quite small. If it was huge number the power of study would be good.

We did not evaluate the health cost and psychological impact of obesity and pregnancy. In contrast Susan Y, Chu et al in New England Journal of Medicine showed that a maternal BMI higher than normal is associated with greater use of health care service which has substantial economic implication. 13

Now the question is how to combat this situation? Does the obese women need weight lost surgery? No, weight surgery is not recommended as it may lead to some nutritional deficiency. Rather all obese women should make weight reduction effort well before she attempt to conceive.

\section{Conclusion:}

The maternal obesity has major adverse effects on pregnancy outcome, economic pressure and parent psychology. Pregnancy among obese women must be classified as high risk pregnancy.
Therefore weight reduction should be one of the important issue need to be discussed as prepregnancy advice given the significant morbidities assessment with maternal and perinatal outcome we suggest to extend this study in national level.

\section{References :}

1. The world Health Organization. Obesity: Preventing and Managing the Global Epidemic, Geneva. WHO, 199.

2. White plains: Obesity during pregnancy threaten health of both mother and fems March of Dimes Say; N.Y., June 9,2004. http://www.marchofdimes.lcom/abortus/1065112183. asp.

3. Obesity during pregnancy carries bigger price tag; Health Day News; Wednesday, April 2, 2008. http:/www.nlm.nlh.gov/ medlineplus/news/fullstory-62948.html.

4. N Heslehurst, L Lang. J Rankin et al. Obesity in pregnancy: a study of the impact of maternal obesity on NHS maternity services; BJOG 207; 114: 334.342.

5. Gostynetter D, Gutzzwiller F, Kuulasmaa K et al. Analysis of the relationship between total cholesterol, age, body mass index among male and female in the WHO monica project Int. J Obest. Relat Metab disorder 2004; 28: 1083-90.

6. Zhang J, Bricker I. Wray S: poor uterine contractility in obese women. BJOG 2007; 114: 343-348

7. Yung TK, Woodmansee B. Factors that are associated with caesarean delivery in a large private practice; the important of pre-pregnancy body mass index and weight gain: am $\mathrm{J}$ Obstet Gynaecol 2002; 187: 312-8.

8. Pitchard J, Baldwin; Dickey J et al; Blood volume Change in pregnancy and puerperium: 11: Red Blood cell loss and change in apparent blood volume during and following vaginal delivery, caesarean section, caesarean section and total hysterectomy. Am J Obst and Gynae 1992; 84: 1271-82.

9. Lashen H, Fear K, Studee DW. Obesity is associated with increased risk of first trimester and recurrent miscarriage; matched case control study. Hum Report 2004; 19: 1644-6.

10. Ramsay JE, Ferrell W, Crawford L et al; Maternal obesity is associated with dysregulation of metabolic vascular and inflammatory pathway; J Clin Endocrin Metabol 2002; 87: 4231-7.

11. Obesity befre pregnancy linked to childhood weigh problems; science Daily; Dec 5, 005. http://www. sciencedaily. com/ releases/2005/12/05/1205115057.

12. Denison FC. Price J Graham C et al. Maternal obesity length of gestation, risk of postdates pregnancy and spontaneous onset of labour at term; BJOG; 2008 May; 115(6): 720-5.

13. Sasan Y. Chu Phd. M.SPH Donald J Bachman MS. Willam $\mathrm{M}$ et al. Association between obesity drug pregnancy and increased use of health care NEJM -2008; 35: 1444-1453. 